\title{
Comparable three months' outcome of total arterial revascularization versus conventional coronary surgery: Copenhagen Arterial Revascularization Randomized Patency and Outcome trial
}

\author{
Sune Damgaard, MD, ${ }^{\text {a }}$ Jens T. Lund, MD, ${ }^{a}$ Nikolaj B. Lilleør, RN, ${ }^{a}$ Mario J. Perko, MD, DMSc, ${ }^{a}$ Kåre Sander, MD, DMSc, ${ }^{a}$ \\ Blagoja Dimo, MD, ${ }^{a}$ Maiken B. Jensen, MD, ${ }^{b}$ Jan K. Madsen, MD, DMSc, ${ }^{d}$ Henning Kelbæk, MD, DMSc, ${ }^{c}$ and \\ Daniel A. Steinbrüchel, MD, DMSc ${ }^{\mathrm{a}}$
}

From the Departments of Cardiothoracic Surgery, ${ }^{a}$ Cardiothoracic Anesthesia, ${ }^{\text {b }}$ Cardiology, ${ }^{\mathrm{c}}$ Rigshospitalet, Copenhagen University Hospital, Denmark; and Department of Cardiology, Gentofte Hospital, ${ }^{\mathrm{d}}$ Copenhagen University Hospital, Hellerup, Denmark.

Funded by the Danish Heart Foundation and Lundbeck Foundation.

Received for publication May 16, 2007; revisions received Sept 25, 2007; accepted for publication Oct 5, 2007.

Address for reprints: Sune Damgaard, MD, Department of Cardiothoracic Surgery RT 2152, Rigshospitalet, Copenhagen University Hospital, Blegdamsvej 9, 2100 Copenhagen, Denmark (E-mail: sunedamgaard@ dadlnet.dk).

J Thorac Cardiovasc Surg 2008;135:106975

\section{$0022-5223 / \$ 34.00$}

Copyright $(\subset 2008$ by The American Association for Thoracic Surgery

doi:10.1016/j.jtcvs.2007.10.039
Objective: The in-hospital safety of total arterial revascularization for coronary artery bypass surgery seems to be comparable to conventional revascularization, but randomized trials evaluating this are few and data on complications in the postoperative months are sparse.

Methods: In a randomized single-center trial, 331 patients underwent total arterial revascularization using single or bilateral internal thoracic and radial arteries versus conventional revascularization using the left internal thoracic artery and saphenous vein grafts. We report the results from 3 months' follow-up.

Results: The mean age of patients was $59 \pm 8$ years, and 39 were women $(12 \%)$. The median EuroSCORE was 2 (interquartile range 1-4). The arterial group comprised 161 patients, and the conventional group comprised 170 patients. The mean number of bypasses in the arterial group was $2.9 \pm 0.9$ versus $3.2 \pm 0.9$ in the conventional group $(P=.004)$. Three months' follow-up for the arterial versus conventional groups showed the following: deaths: $1(0.6 \%)$ versus 0 ; stroke: $3(1.9 \%)$ versus $3(1.8 \%)$; myocardial infarction: $6(3.7 \%)$ versus $4(2.4 \%)$; sternal wound reoperation: 4 $(2.5 \%)$ versus $0(P=.054)$; arm and leg wound complications requiring hospitalization: $3(1.9 \%)$ versus $6(3.5 \%)(P=.50)$, respectively.

Conclusion: These results confirm previous reports that total arterial revascularization can be performed with low in-hospital morbidity and mortality. Further, in the 3 postoperative months, total arterial revascularization did not lead to more complications or admissions than conventional surgery. Arterial grafting was performed with significantly fewer bypasses, but no differences in anginal status were seen after 3 months. A tendency toward more sternal complications after arterial grafting was observed, but clinical outcomes were comparable to conventional grafting.

$\mathrm{C}$ oronary surgery is a well-documented operative procedure, but the main factors influencing long-term outcome have not undergone scientific scrutiny. The standard conduits for coronary artery bypass grafting (CABG) have long been the left internal thoracic artery (LITA) and saphenous vein grafts. Bypass graft patency is an important factor to predict patient outcome after CABG, and the unsatisfactory long-term results of vein grafts have led to an increased use of arterial grafts. ${ }^{1}$ The internal thoracic artery (ITA) offers patients a survival benefit and superior graft patency compared with vein grafts. ${ }^{2}$ The use of bilateral internal thoracic artery (BITA) grafts seems to improve survival even further. ${ }^{3}$ The need for additional grafts and concern about sternal complications after BITA harvest have increased the use of the radial artery. The seemingly superior patency rates compared with vein grafts have led to its revival. ${ }^{4}$ The combination of ITA and radial artery grafts 


\section{Abbreviations and Acronyms}

BITA = bilateral internal thoracic artery

$\mathrm{CABG}=$ coronary artery bypass grafting

ITA $=$ internal thoracic artery

LAD $=$ left anterior descending

LITA $=$ left internal thoracic artery

PCI = percutaneous coronary intervention

RITA $=$ right internal thoracic artery

$\mathrm{TAR}=$ total arterial revascularization

for total arterial revascularization (TAR) is scientifically accepted as a potentially superior treatment but is not commonly used. ${ }^{5,6}$ The evidence for its benefits is sparse. Few large retrospective comparative series and randomized trials show signs of superior graft patency and clinical outcome. ${ }^{7-9}$ However, one randomized trial did not show differences in clinical outcome or patency after 5 years. ${ }^{10}$

The postoperative in-hospital safety and morbidity after TAR seems to be comparable to that of conventional surgery, ${ }^{7-9}$ but the impact on the months after patient discharge is unknown. We compared CABG with the use of LITA or BITA and the radial artery (ie, TAR) vs conventional revascularization using LITA and saphenous vein grafts, in relatively unselected patients with 2- or 3-vessel coronary artery disease. In this article we focus on short-term periand postoperative mortality and morbidity.

\section{Materials and Methods \\ Trial Design}

Patients were randomly allocated to 2 groups: TAR (primarily LITA or BITA, and radial artery) or conventional revascularization (LITA and vein grafts). The primary outcome measures are angiographic 1and 5-year distal anastomotic patency and cardiac event-free survival at 1,5 , and 10 years postoperatively. Secondary outcome measures are perioperative mortality and morbidity.

\section{Ethics}

The trial was conducted in accordance with the Helsinki Declaration, is registered with ClinicalTrials.gov (number: NCT00159991), and was approved by the Regional Research Ethics Committee for Copenhagen (number: [KF] 01-137/01). The funding agencies were not involved in the data interpretation or other aspects of the trial.

\section{Statistics}

Sample size was calculated according to the primary outcome measure: 5-year distal anastomotic patency in the 2 groups. An absolute patency difference of $15 \%$ in favor of TAR was regarded as clinically relevant. To detect a difference of this magnitude at 5 years, $15 \%$ improved patency for arterial grafts $(85 \%$ vs $70 \%)$, with a $90 \%$ power and $5 \%$ level of significance, the group sizes were $\mathrm{N}=$ $150 .^{11}$ A total of 331 patients were included. Data were entered into an Access database (Microsoft 2000; Microsoft Corp, Redmond, Wash) and analyzed by intention to treat principles using the Statistical Package for the Social Sciences 13.0 (SPSS Inc,
Chicago, Ill). Normally distributed continuous data were presented as mean and standard deviation and analyzed using unpaired $t$ test. Median and quartiles and the Mann-Whitney test were used for not normally distributed continuous data. Categoric data are presented as number and percentages and analyzed using the chi-square test with continuity correction or the Fisher exact test as appropriate. All tests were 2-tailed.

\section{Patient Inclusion}

The day before surgery, patients were informed, written and oral consent were obtained, and included patients received a trial number and randomization code. Random allocation was stratified by sex and diabetes state (insulin requiring). The coded randomization envelopes were kept in a locked room at the surgical ward. A nurse without relation to the trial handled and opened the envelopes.

\section{Inclusion Criteria}

Patients with 2- or 3-vessel coronary artery disease referred for elective or urgent $\mathrm{CABG}$ ( $>1$ graft planned) were eligible provided they were aged less than 70 years with a left ventricular ejection fraction greater than $35 \%$. Patients were required to have a normal Allen's test result and be able to give informed consent.

\section{Exclusion Criteria}

Patients were excluded from the trial for the following reasons: in case of aneurysm of the left anterior descending (LAD) coronary artery, concurrent malignant disease with expected survival less than 5 years, unsuitable saphenous vein grafts evaluated preoperatively, emergency operation, other concomitant heart surgery, or reoperation.

\section{Anesthesia}

Regardless of the type of revascularization, patients were anesthetized in the same manner using midazolam, thiopental, fentanyl, pancuronium, and isoflurane $0.4 \%$ to $1.0 \%$. Infusion of propofol was started after the end of perfusion. The infusion of nitroglycerin was started before the aortic crossclamp was released.

\section{Surgery}

For surgery, median sternotomy and normothermic extracorporeal circulation with primarily cold blood cardioplegia were used. The radial artery or saphenous vein was harvested by the open technique and the LITA or both thoracic arteries were prepared as pedicles. Both radial artery and vein grafts were stored in a solution of verapamil $5 \mathrm{mg}$, nitroglycerin $2.5 \mathrm{mg}$, $500 \mathrm{IU}$ of heparin, $0.2 \mathrm{~mL}$ of $8.4 \%$ sodium bicarbonate, and $300 \mathrm{~mL}$ of Ringer's solution. ${ }^{12}$ The same surgeons performed both types of operations and contributed equally to both groups. The operating surgeon decided how to perform the revascularization. A body mass index greater than $35 \mathrm{~kg} /$ $\mathrm{m}^{2}$ combined with insulin-requiring diabetes was a contraindication for the use of BITA. The radial artery was used as a single or sequential graft and anastomosed proximally to the aorta or used as a composite graft. The right internal thoracic artery (RITA) was primarily used as a pedicled graft. Saphenous vein grafts were proximally anastomosed to the aorta and used as single and sequential grafts. The LITA was primarily used as a graft to the LAD with or without jumps to diagonal branches. Proximal aortic anastomoses were sewn with Prolene 6-0 for arterial grafts and Prolene 5-0 for vein grafts. All distal anastomoses and composite arterial graft anastomoses 
were performed with Prolene 7-0. The diameters of target vessels were graded smaller or larger than $1.5 \mathrm{~mm}$ by use of an intraluminal probe.

\section{Postoperative Care}

The nitroglycerin infusion was continued to 6 AM the morning after surgery in a dose of at least $0.5 \mu \mathrm{g} / \mathrm{kg} / \mathrm{min}$ unless low blood pressure prohibited this. From postoperative day 1, all patients in both groups received amlodipine $5 \mathrm{mg}$ increased to $10 \mathrm{mg}$ for 3 months if tolerated. Aspirin and statin treatment were standard for all patients.

\section{Three-month Follow-up}

Clinical follow-up was conducted 1 to 2 months postoperatively at referring hospitals. At 3 months, patients filled in a questionnaire answering if there had been any admissions, complications, or change in medication. Patients reporting complications were contacted by telephone and seen by a project surgeon or cardiologist in the outpatient clinic if indicated. All admissions within 90 days after the operation were double-checked in the national Danish patient admission database (Green System, CSC Scandihealth), which stores diagnoses and discharge letters from admissions at almost all hospitals in Denmark. The hospitals not included are not in regions where any of the trial patients lived, and no patients reported being admitted to any of these hospitals.

\section{Results}

\section{Patient Inclusion}

Of 1969 isolated first-time CABG procedures (February 21, 2002, to February 22, 2005), 1136 patients were available for screening. For flowchart, see Figure 1.

\section{Baseline Data}

There were no differences in baseline data between the 2 groups except that there were more patients in the conventional group with previous stroke or transient cerebral ischemia (Table 1). Overall, the indications for coronary angiography were as follows: stable angina, 55.6\%; non-ST-elevation myocardial infarction, $26.6 \%$; primary percutaneous coronary intervention (PCI) for ST-elevation myocardial infarction, 8.5\%; and unstable angina, $7.9 \%$. Preoperatively, $91.5 \%$ of patients were taking aspirin (1-week pause), $28.7 \%$ of patients were taking clopidogrel (1-week pause), $84.3 \%$ of patients were taking statins, $27.8 \%$ of patients were taking angiotensin-converting enzyme inhibitors, $11.8 \%$ of patients were taking angiotensin receptor blockers, $76.7 \%$ of patients were taking beta-blockers, $21.5 \%$ of patients were taking calcium channel blockers, and $58.3 \%$ of patients were taking nitrates. At inclusion, $49.6 \%$ of patients were smokers.

\section{Operative Data}

TAR group. It took a mean of 21 extra minutes to prepare the arterial conduits (95\% confidence interval 10-31 minutes), and blood cardioplegia was more often used (Table 2). LITAs were used as a sequential grafts in 19 cases (11.8\%), and RITAs were used as free grafts in 12 of 77 cases $(15.6 \%)$. The radial artery was used as a sequential graft in 54 of 128 patients $(42.2 \%)$ and proximally anastomosed to the aorta in 96 patients $(75.0 \%)$. In 24 patients $(14.9 \%)$, a LITA to radial artery composite graft was constructed,
1136 patients available for screening

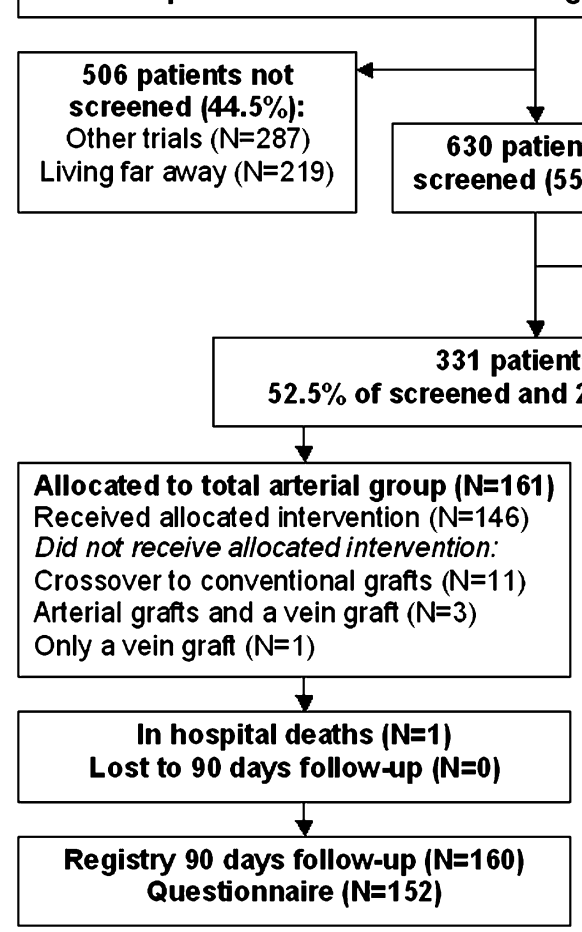

299 patients excluded or did not fulfil inclusion criteria:

Radial artery not usable: 79 (12.5\%)

Logistic reasons: $81(12.9 \%)$

Patient refused: $69(11.0 \%)$

Language problems: $22(3.5 \%)$

Co-morbidities ${ }^{\star}: 20(3.2 \%)$

Surgeon refused: $14(2.2 \%)$

Vein not usable: $10(1.6)$

Othert: 4 (0.6\%) (All \% of screened)
Figure 1. Flowchart. *Extreme obesity, severe renal disease, severe handicap, abuse or psychiatric disease, and severe femoral atherosclerosis. ${ }^{\dagger}$ Takayasu arteritis, concomitant ablation for atrial fibrillation, urgent operation. 
TABLE 1. Preoperative clinical status

\begin{tabular}{|c|c|c|}
\hline & \multicolumn{2}{|c|}{ Type of revascularization } \\
\hline & $\begin{array}{c}\text { Total arterial } \\
(\mathbf{n}=161)\end{array}$ & $\begin{array}{c}\text { Conventional } \\
(\mathrm{n}=170)\end{array}$ \\
\hline Female sex & $19(11.8)$ & $20(11.8)$ \\
\hline Age, y & $59 \pm 8$ & $59 \pm 8$ \\
\hline Body mass index, $\mathrm{kg} / \mathrm{m}^{2}$ & $27 \pm 4$ & $28 \pm 4$ \\
\hline CCS class $\geq 3$ & $51(31.7)$ & $43(25.3)$ \\
\hline NYHA class $\geq 3$ & $35(21.7)$ & $27(15.9)$ \\
\hline $\mathrm{Ml}<90 \mathrm{~d}$ & $56(34.8)$ & $67(39.4)$ \\
\hline Atrial arrhythmia & $8(5.0)$ & $4(2.4)$ \\
\hline Previous $\mathrm{PCl}$ & $31(19.3)$ & $27(15.9)$ \\
\hline Hypertension & $82(50.9)$ & $81(47.6)$ \\
\hline Hypercholesterolemia & $140(87.0)$ & $147(86.5)$ \\
\hline Total cholesterol, mmol/L & $5.2 \pm 1.2$ & $5.3 \pm 1.2$ \\
\hline Nonelective surgery & $57(35.4)$ & $65(38.2)$ \\
\hline EuroSCORE* & $21-3$ & $31-4$ \\
\hline COPD & $9(5.6)$ & $14(8.2)$ \\
\hline Peripheral arterial disease & $18(11.2)$ & $20(11.8)$ \\
\hline Cerebrovascular disease & $3(1.9)$ & $13(7.6)$ \\
\hline Creatinine $>200 \mathrm{mmol} / \mathrm{L}$ & $1(0.6)$ & $2(1.2)$ \\
\hline Diabetes: insulin & $6(3.7)$ & $9(5.3)$ \\
\hline Diabetes: diet/tablets & $33(20.5)$ & $34(20.0)$ \\
\hline LMS stenosis only & $13(8.1)$ & $14(8.2)$ \\
\hline 2-vessel disease & $44(27.3)$ & $53(31.2)$ \\
\hline 3-vessel disease & $100(62.1)$ & $103(60.6)$ \\
\hline Ejection fraction $35 \%-49 \%$ & $48(29.8)$ & $42(24.7)$ \\
\hline Ejection fraction $\geq 50 \%$ & $113(70.2)$ & $128(75.3)$ \\
\hline
\end{tabular}

CCS, Canadian Cardiovascular Society; NYHA, New York Heart Association, $\mathrm{MI}$, myocardial infarction; $P C l$, percutaneous coronary intervention; $C O P D$, chronic obstructive pulmonary disease; $L M S$, left main stem coronary artery. ${ }^{*}$ Presented as number $(\%)$, mean \pm standard deviation, and ${ }^{*}$ median and quartiles.

and in 15 patients $(9.3 \%)$ a RITA to radial artery extension graft was constructed. The 11 crossovers to conventional revascularization were the result of inadvertent error by the surgeon in 6 cases ( 4 because of a positive Allen's test performed erroneously after randomization by the operating surgeon and 1 because the radial artery was of poor quality). Other protocol violations were as follows: 5 patients received only a LITA to the LAD because this was the only graftable vessel in 4 patients and the only bypass needed after review of the preoperative angiography in 1 patient. This was also the case in 2 patients receiving only a radial artery graft and 1 patient erroneously receiving a vein graft, all to the right coronary artery. One patient received a radial artery to the LAD because the LITA was of poor quality and a borderline obtuse marginal stenosis was scheduled for PCI. Three patients received a vein graft in addition to arterial grafts because of insufficient arterial graft length. Two patients with insulin-requiring diabetes and body mass index greater than 35 had BITA grafts.

Conventional group. Saphenous veins were used as sequence grafts in 86 patients $(50.6 \%)$. Of the 3 crossovers to TAR, 2 were due to poor vein graft material and 1 was due to inadvertent error by the surgeon. One patient received a RITA graft in addition to a LITA and vein graft because there was no more usable saphenous vein material. Six patients received a jump LITA graft to a diagonal instead of a vein graft. The inoperable patient had unexpected pericardial carcinosis from lung cancer; he recovered fairly well postoperatively and underwent incomplete revascularization by PCI during another admission. Other protocol violations were as follows: one patient received only a LITA to the LAD because this was the only graftable vessel, 1 patient was aged more than 70 years at inclusion, 6 patients underwent operation by non-trial surgeons, 1 patient had an ejection fraction less than $35 \%$, and 1 patient underwent concomitant carotid endarterectomy.

Postoperative stay. One patient in the TAR group died of aortic rupture at reoperation of suspected graft failure a few hours after the primary operation (Table 3). Two patients in the TAR group had graft occlusion diagnosed at angiography after signs of myocardial infarction (creatine kinase $\mathrm{MB}>80$ $\mu \mathrm{g} / \mathrm{L}) ; 1$ patient with an occluded LITA underwent PCI, and 1 patient with an occluded radial artery underwent reoperation. Four patients in the conventional group underwent angiography because of signs of myocardial infarction: One patient had open grafts, 2 patients underwent reoperation for vein graft occlusion, and 1 patient, who had an occluded LITA and 1 occluded and 1 open vein graft, did not undergo reoperation because of extensive diffuse atherosclerosis. PCI was attempted without success. The patient recovered and was discharged in relatively good condition. Two patients in the conventional group had a perioperative stroke, 1 with paraplegia and 1 with only aphasia who recovered almost completely before discharge. The $8 \%$ of patients who were not discharged directly to home were transferred to referring hospitals for rehabilitation.

Three-month follow-up. There were no deaths or myocardial infarctions reported and no significant differences in complications requiring hospitalization (Table 4). Aspirin was taken by $95.8 \%$ of patients, statins were taken by $91.7 \%$ of patients, beta-blockers were taken by $73.7 \%$ of patients, nitrates were taken by $3.5 \%$ of patients, and $22.4 \%$ of patients were still smoking. There were no significant differences between groups, except 135 patients $(88.8 \%)$ in the TAR group and 121 patients $(75.6 \%)$ in the conventional group had taken calcium channel blockers $(P=.004)$.

Per protocol analysis. Per protocol analysis of data from the in-hospital stay and 3 months' follow-up did not influence the results (135 patients in the TAR group vs 147 patients in the conventional group).

\section{Discussion}

Our results show comparable outcome 3 months after TAR versus conventional revascularization. Performing randomized trials of surgical procedures has never been straightforward. 
TABLE 2. Operative data

\begin{tabular}{|c|c|c|c|}
\hline & \multicolumn{2}{|c|}{ Type of revascularization } & \multirow[b]{2}{*}{$P$ value } \\
\hline & $\begin{array}{c}\text { Total arterial } \\
(\mathrm{n}=161)\end{array}$ & $\begin{array}{c}\text { Conventional } \\
(n=170)\end{array}$ & \\
\hline Operation time, $\min$ & $192 \pm 51$ & $172 \pm 45$ & .000 \\
\hline CPB time & $73 \pm 22$ & $70 \pm 23$ & .281 \\
\hline Crossclamp time & $45 \pm 15$ & $43 \pm 15$ & .398 \\
\hline Blood cardioplegia & $130(83.3)$ & $114(69.5)$ & .006 \\
\hline Use of inotropic agents & $23(14.3)$ & 19 (11.2) & .494 \\
\hline Tranexamic acid & $140(87.0)$ & $141(82.9)$ & .386 \\
\hline Aprotinin & $8(5.0)$ & $8(4.7)$ & 1.000 \\
\hline \multicolumn{4}{|l|}{ Patients with: } \\
\hline Only BITA & $15(9.3)$ & $2(1.2)$ & - \\
\hline BITA and RA & $61(37.9)$ & $1(0.6)$ & - \\
\hline LITA and RA & $63(39.1)$ & $1(0.6)$ & - \\
\hline LITA and SVG & $12(7.5)$ & $160(94.1)$ & - \\
\hline Only LITA & $5(3.1)$ & $2(1.2)$ & - \\
\hline Only RA & $3(1.9)$ & 0 & - \\
\hline Only SVG & $1(0.6)$ & $3(1.8)$ & - \\
\hline Only RITA and RA & $1(0.6)$ & 0 & - \\
\hline Complete revascularization & $128(79.5)$ & $141(82.9)$ & .509 \\
\hline Distal anastomoses & 466 & 542 & - \\
\hline Distal anastomoses/patient & $2.9 \pm 0.9$ & $3.2 \pm 0.9$ & .004 \\
\hline \multicolumn{4}{|l|}{ Patients with: } \\
\hline $\begin{array}{l}0 / 1 / 2 / 3 / 4 / \geq 5 \text { distal } \\
\text { anastomoses }(\%)^{*}\end{array}$ & $0 / 8 / 44 / 70 / 35 / 4(0 / 5 / 27 / 43 / 22 / 2)$ & 1/1/37/71/47/13 (1/1/22/42/28/8) & .033 \\
\hline Target vessel $<1.5 \mathrm{~mm}$ & $138(29.6)$ & $162(29.9)$ & .979 \\
\hline
\end{tabular}

$C P B$, Cardiopulmonary bypass; LITA, left internal thoracic artery; RITA, right internal thoracic artery; BITA, bilateral internal thoracic artery; $R A$, radial artery; $S V G$, saphenous vein graft. Presented as number $(\%)$ and mean \pm standard deviation. Chi-square and $t$ tests. ${ }^{*}$ Percentages are rounded numbers.

Numerous factors complicate and influence the active intervention itself, blinding is rarely possible, and patients cannot actually withdraw their consent once the operation has been performed. These are obviously not the only difficulties we have experienced, but despite the challenges, randomized trials are necessary because relatively few surgical procedures are evidence-based. This article reports the first results from the largest randomized trial comparing TAR with conventional CABG.

\section{Baseline Data}

The predominance of patients with cerebrovascular disease in the conventional group is considered to be due to chance because of the relatively limited number of patients. More than $50 \%$ of screened patients were included in the trial, thereby yielding a relatively high internal validity. Moreover, the fact that $30 \%$ of vessel diameters were less than $1.5 \mathrm{~mm}$ documents that unselected patients were enrolled.

\section{In-hospital}

Overall, $81 \%$ of patients received bypass grafts to all intended target vessels. Even so, the patients in the TAR group received a mean of 0.3 fewer distal anastomoses (95\% confidence interval 0.1-0.5). Saphenous veins seem to offer more material for grafting, and perhaps coronary lesions of minor importance are left untreated more often in arterial grafting. This is supported by the fact that the prevalence of angina pectoris, according to the Canadian Cardiovascular Society classification, was the same in the 2 groups after 3 months. Muneretto and colleagues ${ }^{8}$ reported a mean distal anastomosis number of 2.8 per patient in their trial of TAR.

The longer operation time and BITA harvest in itself may have accounted for the tendency toward more transfusions, primarily red blood cells, in the TAR group. BITA harvest has been found to increase operation time and postoperative bleeding. ${ }^{13}$ More patients in the TAR group received blood cardioplegia, partly because nonproject surgeons using crystalloid cardioplegia performed operations in 6 patients in the conventional group. This may have masked a difference in the postoperative levels of creatine kinase $\mathrm{MB}$ and the need for inotropes, ${ }^{14}$ but because only 16 (14\%) more patients in the arterial group than in the conventional group had blood cardioplegia, the impact on our data seems limited.

As expected, the in-hospital perioperative morbidity and mortality were similar in the 2 groups. Serious complications were few in these low- to medium-risk patients. There was a trend toward more arm wound complications in the TAR group than leg wound complications in the conventional 
TABLE 3. Postoperative stay

\begin{tabular}{|c|c|c|c|}
\hline & \multicolumn{2}{|c|}{ Type of revascularization } & \multirow[b]{2}{*}{$\begin{array}{c}P \\
\text { value }\end{array}$} \\
\hline & $\begin{array}{c}\text { Total arterial } \\
(n=161)\end{array}$ & $\begin{array}{c}\text { Conventional } \\
(\mathrm{n}=170)\end{array}$ & \\
\hline Length of stay, $d$ & $6.9 \pm 2.1$ & $7.1 \pm 3.1$ & .613 \\
\hline Ventilation time, $\mathrm{h}^{*}$ & $64-10$ & $64-10$ & .444 \\
\hline Ventilator $>24 \mathrm{~h}$ & $2(1.2)$ & $4(2.4)$ & .685 \\
\hline Peak CK-MB, $\mu \mathrm{g} / \mathrm{L}^{*}$ & 19 14-25 & $2015-26$ & .277 \\
\hline Inotropes & $24(14.9)$ & $25(14.7)$ & 1.000 \\
\hline Atrial fibrillation & $52(32.3)$ & $48(28.2)$ & .493 \\
\hline Transfusion & $49(30.4)$ & $37(21.8)$ & .094 \\
\hline $\begin{array}{l}\text { Superficial sternal } \\
\text { wound infection }\end{array}$ & 0 & $2(1.2)$ & .499 \\
\hline $\begin{array}{l}\text { Arm or leg wound } \\
\text { complication }\end{array}$ & $5 / 130(3.8)$ & $1 / 167(0.6)$ & .090 \\
\hline $\begin{array}{l}\text { Reoperation for } \\
\text { bleeding }\end{array}$ & $3(1.9)$ & $4(2.4)$ & 1.000 \\
\hline $\begin{array}{l}\text { Myocardial infarction } \\
\quad(\text { CK-MB > 80) }\end{array}$ & $6(3.7)$ & $4(2.4)$ & .533 \\
\hline Re-angiography & $2(1.2)$ & $4(2.4)$ & .685 \\
\hline $\begin{array}{l}\text { Reoperation for graft } \\
\text { failure }\end{array}$ & $2(1.2)$ & $2(1.2)$ & 1.000 \\
\hline $\mathrm{PCl}$ & $1(0.6)$ & 0 & .486 \\
\hline IABP & $2(1.2)$ & 0 & .236 \\
\hline Stroke & 0 & $2(1.2)$ & .499 \\
\hline Deaths & $1(0.6)$ & 0 & .486 \\
\hline $\begin{array}{l}\text { Discharged directly } \\
\text { to home }\end{array}$ & $147(91.3)$ & $158(92.9)$ & .727 \\
\hline
\end{tabular}

$C K-M B$, Creatine kinase $\mathrm{MB} ; \mathrm{PCl}$, percutaneous coronary intervention; $I A B P$, intraaortic balloon pump. *Presented as number $(\%)$, mean \pm standard deviation, and *median and quartiles. Mann-Whitney, $t$, Fisher exact, and chi-square tests.

group: Four patients had arm sensory disturbances, 1 patient had reduced hand force, and 1 patient had leg sensory disturbances. This could partly be because of an increased awareness of complications from the arm compared with the leg.

\section{Three-month Follow-up}

It seems that patients undergoing TAR do not experience more complications in the short-term postoperative period, but it is surprising that a quarter of all patients had been readmitted. This could be a result of the relatively short postoperative hospital stays. Freedom from angina (Canadian Cardiovascular Society class 1) at 3 months was more than $90 \%$, even though $19 \%$ of patients were left with untreated coronary lesions.

\section{Wound Complications}

Four patients in the TAR group required readmission and sternal rewiring, 1 because of deep infection. In 3 patients, BITA was used. No patients had diabetes or a body mass index greater than 35 . The difference between groups was only borderline significant, but the use of BITA in comparison with a single ITA seemed to increase the risk of sternal
TABLE 4. Three months' follow-up

\begin{tabular}{lccr}
\hline & \multicolumn{2}{c}{ Type of revascularization } & \\
\cline { 2 - 3 } & $\begin{array}{c}\text { Total arterial } \\
(\mathbf{n}=\mathbf{1 6 0})\end{array}$ & $\begin{array}{c}\text { Conventional } \\
(\mathbf{n}=\mathbf{1 7 0})\end{array}$ & $\begin{array}{c}\boldsymbol{P} \\
\text { value }\end{array}$ \\
\hline Patients readmitted & $39(24.4)$ & $43(25.3)$ & .948 \\
Readmission for: & & & \\
Arm or leg wound complication & $3(1.9)$ & $6(3.5)$ & .503 \\
Atrial fibrillation & $6(3.8)$ & $11(6.5)$ & .385 \\
Observation for MI & $9(5.6)$ & $6(3.5)$ & .516 \\
Thoracentesis & $6(3.8)$ & $4(2.4)$ & .532 \\
Sternal rewiring & $4(2.5)$ & 0 & .054 \\
Reoperation for PE & 0 & $1(0.6)$ & 1.000 \\
Pneumonia & $2(1.3)$ & $6(3.5)$ & .285 \\
PCl & 0 & $1(0.6)$ & 1.000 \\
Stroke & $3(1.9)$ & $1(0.6)$ & .358 \\
Other cardiac-related & $9(5.6)$ & $6(3.5)$ & .516 \\
Other noncardiac & $8(5.0)$ & $10(5.9)$ & .912 \\
& & & \\
\hline
\end{tabular}

\begin{tabular}{lccl}
\hline \multicolumn{1}{c}{ Questionnaire follow-up: } & (n = 152) & (n = 160) & \\
\hline CCS class 1 & $142(93.4)$ & $152(95.0)$ & .723 \\
CCS class 2 & $10(6.6)$ & $7(4.4)$ & \\
CCS class 3 & 0 & $1(0.6)$ & \\
NYHA class 1 to 2 & $147(96.7)$ & $152(95.0)$ & .637 \\
NYHA class 3 & $5(3.3)$ & $8(5.0)$ & \\
Patients with atrial fibrillation & $10(6.3)$ & $15(8.8)$ & .500 \\
Arm or leg motor dysfunction & $6 / 129(4.7)$ & $19 / 160(11.9)$ & .050 \\
Arm or leg sensor dysfunction & $35 / 129(27.1)$ & $54 / 160(33.8)$ & .279 \\
Arm or leg wound complication & $22 / 129(17.1)$ & $38 / 160(23.8)$ & .212 \\
Total cholesterol, mmol/L & $4.2 \pm 1.0$ & $4.3 \pm 0.9$ & .778 \\
\hline
\end{tabular}

$M I$, Myocardial infarction; $P E$, pericardial effusion; $P C I$, percutaneous coronary intervention; CCS, Canadian Cardiovascular Society; NYHA, New York Heart Association. Other cardiac-related = sudden loss of consciousness, observation for suspected pulmonary embolism/pericardial effusion. Other noncardiac $=$ urogenital, gastrointestinal or malignancy. *Presented as number (\%). Chi-square, Fisher exact, and $t$ tests.

dehiscence 10-fold: BITA 3 of 79 (3.8\%) versus single ITA 1 of $250(0.4 \%)$, relative risk $9.53,95 \%$ confidence interval 1.01 to $90.34, P=.044$. All cases of sternal dehiscence are obviously not included in this because not all patients are diagnosed within 3 months. Follow-up after 1 year will help to clarify this.

Fewer patients in the TAR group seemed to experience any sort of motor dysfunction (primarily reduced strength) in the arm or hand compared with patients in the conventional group who had experienced motor dysfunction in the leg or foot. Approximately one third of patients in both groups reported sensory disturbances (numbness and paresthesia) from the arm and hand, the leg and foot, or the scar. Patients' perception of sensory disturbances after radial artery harvest is probably more common than previously reported. Up to $68 \%$ of patients report any sort of sensory disturbances; however, they are self-limiting and of only minor importance to patients. ${ }^{15}$ Approximately $20 \%$ of patients in both groups 
reported that they had been to their general practitioner because of complicated arm or leg wound healing or superficial wound infection. However, only 1 patient in the TAR group had been admitted for arm wound infection and treated with intravenous antibiotics; another patient had an arm wound hematoma surgically evacuated. A third patient in the TAR group was admitted for an infected leg wound. The 6 patients in the conventional group who were admitted with an infected leg wound were treated with intravenous antibiotics, and 2 patients also needed surgical revision.

\section{Conclusions}

These first results from the Copenhagen Arterial Revascularization Randomized Patency and Outcome (CARRPO) trial comparing total arterial with conventional revascularization confirm previous reports that TAR can be performed with low in-hospital morbidity and mortality. During the 3 postoperative months, arterial revascularization did not lead to more complications and admissions than conventional CABG. Arterial grafting may lead to slightly fewer bypasses, but clinical outcomes were comparable to conventional grafting. The results from the 1-year follow-up will help to clarify whether arterial grafts lead to superior graft patency and clinical outcome.

\section{References}

1. Fitzgibbon GM, Kafka HP, Leach AJ, Keon WJ, Hooper GD, Burton JR. Coronary bypass graft fate and patient outcome: angiographic follow-up of 5,065 grafts related to survival and reoperation in 1,388 patients during 25 years. J Am Coll Cardiol. 1996;28:616-26.

2. Loop FD, Lytle BW, Cosgrove DM, Stewart RW, Goormastic M, Williams GW, et al. Influence of the internal-mammary-artery graft on 10-year survival and other cardiac events. N Engl J Med. 1986;314:1-6.

3. Taggart DP, D'Amico R, Altman DG. Effect of arterial revascularisation on survival: a systematic review of studies comparing bilateral and single internal mammary arteries. Lancet. 2001;358:870-5.
4. Desai ND, Cohen EA, Naylor CD, Fremes SE, the Radial Artery Patency Study Investigators. A randomized comparison of radial-artery and saphenous-vein coronary bypass grafts. N Engl J Med. 2004;351:2302-9.

5. Baskett RJ, Cafferty FH, Powell SJ, Kinsman R, Keogh BE, Nashef SA. Total arterial revascularization is safe: multicenter ten-year analysis of 71,470 coronary procedures. Ann Thorac Surg. 2006;81:1243-8

6. Kappetein AP, Dawkins KD, Mohr FW, Morice MC, Mack MJ, Russell ME, et al. Current percutaneous coronary intervention and coronary artery bypass grafting practices for three-vessel and left main coronary artery disease: insights from the SYNTAX run-in phase. Eur J Cardiothorac Surg. 2006;29:486-91.

7. Zacharias A, Habib RH, Schwann TA, Riordan CJ, Durham SJ, Shah A. Improved survival with radial artery versus vein conduits in coronary bypass surgery with left internal thoracic artery to left anterior descending artery grafting. Circulation. 2004;109:1489-96.

8. Muneretto C, Negri A, Manfredi J, Terrini A, Rodella G, ElQarra S, et al. Safety and usefulness of composite grafts for total arterial myocardial revascularization: a prospective randomized evaluation. $J$ Thorac Cardiovasc Surg. 2003;125:826-35.

9. Muneretto C, Bisleri G, Negri A, Manfredi J, Metra M, Nodari S, et al. Total arterial myocardial revascularization with composite grafts improves results of coronary surgery in elderly: a prospective randomized comparison with conventional coronary artery bypass surgery. Circulation. 2003;108(suppl II):II29-33.

10. Buxton BF, Raman JS, Ruengsakulrach P, Gordon I, Rosalion A, Bellomo R, et al. Radial artery patency and clinical outcomes: fiveyear interim results of a randomized trial. $J$ Thorac Cardiovasc Surg. 2003;125:1363-70.

11. Altman DG. Clinical trials. In: Altman DG, editor. Practical Statistics for Medical Research. 1st ed. London: Chapman \& Hall; 1995. p. 440-76.

12. He GW. Verapamil plus nitroglycerin solution maximally preserves endothelial function of the radial artery: comparison with papaverine solution. J Thorac Cardiovasc Surg. 1998;115:1321-7.

13. Gansera B, Schmidtler F, Gillrath G, Angelis I, Wenke K, Weingartner J, et al. Does bilateral ITA grafting increase perioperative complications? Outcome of 4462 patients with bilateral versus 4204 patients with single ITA bypass. Eur J Cardiothorac Surg. 2006;30:318-23.

14. Guru V, Omura J, Alghamdi AA, Weisel R, Fremes SE. Is blood superior to crystalloid cardioplegia? A meta-analysis of randomized clinical trials. Circulation. 2006;114(suppl I):I331-8.

15. Saeed I, Anyanwu AC, Yacoub MH, Amrani M. Subjective patient outcomes following coronary artery bypass using the radial artery: results of a cross-sectional survey of harvest site complications and quality of life. Eur J Cardiothorac Surg. 2001;20:1142-6. 